University of Wollongong

Research Online

Faculty of Social Sciences - Papers (Archive) Faculty of Arts, Social Sciences \& Humanities

$1-1-2016$

Meeting Country and Self to Initiate an Embodiment of Knowledge:

Embedding a Process for Aboriginal Perspectives

Anthony D. McKnight

University of Wollongong, anthonym@uow.edu.au

Follow this and additional works at: https://ro.uow.edu.au/sspapers

Part of the Education Commons, and the Social and Behavioral Sciences Commons

Research Online is the open access institutional repository for the University of Wollongong. For further information contact the UOW Library: research-pubs@uow.edu.au 


\title{
Meeting Country and Self to Initiate an Embodiment of Knowledge: Embedding a Process for Aboriginal Perspectives
}

\author{
Abstract \\ Social justice is often the primary framework that directs academics to embed Aboriginal perspectives \\ into teacher education programmes. The effectiveness and limitations of social justice as a catalyst and \\ change agent was examined when six school of education academics from an Australian regional \\ university were introduced to Yuin Country as knowledge holder. This paper argues that social justice in \\ Australian education systems can contribute to the colonial control of knowledge production. At the same \\ time, however, social justice may provide a means for non-Aboriginal people to experience Aboriginal \\ ways of knowing and thereby to diversify their thinking. A cultural experience with Yuin Country played a \\ central role in connecting and separating social justice to provide a balance in relatedness, disrupting the \\ colonial emphasis of Western binary thinking that only separates. The academics shared their ideas and \\ feelings in relation to Aboriginal people and culture before, during and after the cultural experience \\ Mingadhuga Mingayung (McKnight, 2015) of two significant Yuin Mountains on the far south coast of \\ New South Wales. The research described in this paper explored the academics' journey with Country to \\ investigate the role of social justice thinking to unveil and or conceal Aboriginal perspectives as Country.

\section{Keywords} \\ self, knowledge:, country, embedding, initiate, process, embodiment, meeting, perspectives, aboriginal

\section{Disciplines} \\ Education | Social and Behavioral Sciences

\section{Publication Details} \\ McKnight, A. (2016). Meeting Country and Self to Initiate an Embodiment of Knowledge: Embedding a \\ Process for Aboriginal Perspectives. The Australian Journal of Indigenous Education, 45 (1), 11-22.
}




\begin{abstract}
Social justice is often the primary framework that directs academics to embed Aboriginal perspectives into teacher education programs. The effectiveness and limitations of social justice as a catalyst and change agent was examined when six school of education academics from an Australian regional university were introduced to Yuin Country as knowledge holder. This paper argues that social justice in Australian education systems can contribute to the colonial control of knowledge production. At the same time, however social justice may provide a means for non-Aboriginal people to experience Aboriginal ways of knowing and thereby to diversify their thinking. A cultural experience with Yuin Country played a central role in connecting and separating social justice to provide a balance in relatedness, disrupting the colonial emphasis of Western binary thinking that only separates. The academics shared their ideas and feelings in relation to Aboriginal people and culture before, during and after the cultural experience Mingadhuga Mingayung (Author 2015) of two significant Yuin Mountains on the far south coast of NSW. The research described in this paper explored the academics' journey with Country to investigate the role of social justice thinking to unveil and or conceal Aboriginal perspectives as Country.
\end{abstract}

\title{
Meeting Country and self to initiate an embodiment of knowledge: Embedding a process for Aboriginal perspectives.
}

"They are just hearing the story - isn't that what you call theory? - they are not learning the true body of knowledge" (Gotha cited in Christie 2010, p. 11).

\section{Introduction}

The embedding of Aboriginal perspectives or "Aboriginal histories and cultures", is one of the three Cross Curriculum Priorities to be emphasised in Australian schools, according to the Australian Curriculum Assessment and Reporting Authority (ACARA).

The Aboriginal and Torres Strait Islander priority provides opportunities for all learners to deepen their knowledge of Australia by engaging with the world's oldest continuous living cultures. This knowledge and understanding will enrich their ability to participate positively in the ongoing development of Australia (ACARA 2012).

As indicated by this quote, embedding an Aboriginal perspective in the school curriculum remains focused on knowledge and understanding, rather than utilising Aboriginal educational systems and approaches. At the same time, Australian 
academic discourse on Aboriginal knowing and learning has moved beyond knowledge, understanding and Aboriginal content to a focus on the importance of Aboriginal pedagogies and processes (Moreton-Robinson, Singh, Kolopenuk, Robinson \& Walter, 2012). However, the shift from discourse to enhanced practice in tertiary institutions and schools appears to present a considerable challenge. As Lowe and Yunkaporta (2011) argue, to achieve this successfully requires an extended engagement with Aboriginal systems and processes to obtain relevant pedagogical skills, and understandings of the living protocols. Although there is a growing literature in which the engagement with Aboriginal perspectives within tertiary institutions is being explored (Lampert, Burnett, Martin \& McCrea 2014, McLaughlin 2013, Williamson and Dalal 2007, Dudgeon and Fielder 2006), the embedding of Country, as knowledge system and process, is limited. Country is often placed in the background or misplaced because of the ways colonial knowledge systems and processes undervalue Country's relationship with Aboriginal knowledge. If respect for Aboriginal ways of knowing and learning is to permeate teacher education and teaching in schools, the pedagogy of respectful reciprocal relationships with Country needs to be a priority (Author 2015). Instead the first impulse to embed Aboriginal perspectives in university programs seems to be driven by a social justice imperative.

From a social justice perspective, what is generally regarded as important is addressing "structural disadvantages" that act "to impede the progression of students at school" (Beresford, Partington and Gower 2012, p. 124). While a social justice approach can identify structural blockages, it needs to be asked whether social justice thinking can address the entrenched structural disadvantage that defines the power relationship that 'others' Aboriginal peoples. McLaughlin and Whatman (2011) suggest that to move beyond social justice discourses and practices, the incorporation of "Indigenous knowledge, decolonising methodologies, and research ethics and protocols that guide research and scholarship within academia" (p. 3) is necessary. This paper reports on research that explored how it might be possible to move beyond a social justice approach and explicitly connect with Yuin Country as teacher.

The key focus of this paper, then, is to examine the possibilities afforded by a program, conducted with non-Aboriginal academics, which presents Yuin knowledge as Country in partnership with Western social justice principles. My initial starting point was the assumption that social justice is blinkered by the reliance of its own 
knowledge system (Western) to resolve challenging cross-cultural issues. However, in doing so, I recognise the danger of creating similar blind spots, by just relying on what Greives (2009) names responsive Aboriginal knowledge, which can be just as divisive (Nakata 2013).

This paper will demonstrate how Yuin Country via Mingadhuga Mingayung (Author 2015) can connect with academics' known world of theory (worldview) to prompt them to reflect on their epistemological understandings in ways that provide opportunities for disrupting colonial thinking. As quoted in the above epigraph, Gotha (cited in Christie 2010) states when a story is shared within a classroom "They are not learning the true body of knowledge' (p. 11). To start the journey of learning the whole story or body of knowledge, the learning has to occur with and on Country so the knowledge can be observed, felt and understood on a spiritual level of connectedness. By contrast the classroom closes itself off from the non-human teachers that are required for access to the true body of knowledge. Mingadhuga Mingayung (Author 2015) has been chosen as a term to describe how the Yuin text of the land can be seen so it can be felt on a deep personal level. Mingadhuga Mingayung is an understanding from Country as an observed text. Mingadhuga Mingayung originates from Biamanga (Place of teaching) and Gulaga (Mother Mountain: Yuin creation story), which Uncle Max Harrison (2009) as a Senior Yuin Lawman holds. It was through Gulaga, Biamanga and Uncle Max Harrison's permission that my understanding as an Aboriginal man of this experience of Yuin Country, came into being. Further, it is this experience that planted the seeds for this research to come into being in academia. As I tell the story of this experience, I am at the same time trying to be very conscious of the benefits and pitfalls of working within an insider frame (Smith 2012).

\section{Meeting Country within the turbulence}

The problem of this paper and research occurred in my own body, as I worked within a Western system to challenge a system (Western) and to re-introduce an ancient system of this Country (Yuin), in a respectful manner. The research reported in this

paper was designed to examine the capacity of the dynamic experience of Mingadhuga Mingayung (Author 2015), within a contingent relationship with social justice to shift non-Aboriginal academics' predeterminations on Aboriginal people 
and culture in ways that would assist them to see Country as knowledge holder. In an attempt to achieve this, I worked with an Early Childhood (EC) team in a school of education at an Australian university to design an experience to decolonise/reculturalise the implementation of Aboriginal perspectives within their program, which would meet their philosophy of Aboriginal education. At our first meetings to discuss the possibilities of such a program their philosophy seemed primarily informed by social justice principles to align with the Early Years Learning Framework. For example, in a yarning session held prior to going on Country and experiencing Mindgadhuga Mingayung, one of the six academics in the program, explained her reasons for participating as follows:

If you genuinely have a belief in social justice and understanding and allowing people to be who they are then I think that is a really good you know, ground work. (Kylie, pre Mingadhuga Mingayung yarning session)

The use of 'allowing' in this quote is significant, and indicative of the colonial aspect of social justice. It signifies a power relationship in which a member of the dominant culture can provide permission, retaining a separation of the 'Other' as less than. This is a permission that is still active throughout the discourse surrounding the interactive associations of social justice, decolonization and 'cultural competency'. A consequence of a social justice mindset is that it can create a pattern of thinking that closes down the need to learn more about, or engage in another culture's way of knowing, learning and behaving. A person can fulfill their own or their institution's social justice thinking through demonstrating an understanding of cultural attributes through institutional prerequisites (for example, a two hour indoor workshop on reconciliation). The actual knowledge system and process of the culture is ignored and left rendered as the marginalized other. Nor at the very least is there any acknowledgement of the existence of this pivotal knowledge system and process; and by consequence, the limitations of any indoor learning that does not recognized Aboriginal knowledge systems and processes. Furthermore the individual is not engaged in a thoughtful process of holding a lifelong learning relationship with Country. It is possible, however, for social justice discourses and practices to engage differently with Aboriginal knowledge(s) and peoples. To do so non-Aboriginal people need to be aware of the paternalistic nature of social justice thinking to assist in the process of being open to another source of knowledge. 
The challenge is to reduce colonial social justice thinking for decolonising theorization to occur, while at the same time maintaining social justice principles which assist the individual to became aware of the ways that social justice continually re-establishes colonising knowledge systems and processes. As Smith (2012) states, 'decolonisation must offer a language of possibility, a way out of colonisation' (p. 314). In a Yuin cultural context, Country through the text of the land is the language of possibility to step out of colonisation ways of thinking and doing.

\section{Dipping the Toe into the Water: Storying approach alongside Theory}

Country is space and place of the present in which the future is in the now as we become our past. (Reflection on the meaning of Country, Author, March 2015)

Country is the space and place where Aboriginal and non-Aboriginal people can learn with Country in relationship to everything that is of Country. If an individual has an open mind to see all the living unseen and seen teachers of Country - trees, mountains, water, animals, birds, people, rocks, humidity and all the entities that make up Country - Country provides the stories and the knowledge. Country also provides the space to learn, reflect, challenge, cry, laugh, oppose and agree, while experiencing an ancient story of connection. In the context of the cultural experience described in this paper, Mingadhuga Mingayung provided the stories, place and space through the text of the land. Mingadhuga Mingayung derives from Gulaga, who is as stable as a Mountain, holding the stories the same way since creation, which is right/write there in front of the individual. As Uncle Max Harrison (2009) says, "There is plenty in that library up there, it is the text of the land." (p. 39).

People who visit Country engage with Country's teachings by means of their own epistemological understandings. How these understandings connect with Country is related to what Bhabha (2004) describes as the 'third space'. Bhabha's (2004) third space for Dudgeon and Fielder (2006) 'represents a radical hybrid space - unstable, changing, tenuous, neither here nor there' (p. 401). Gulaga shares the text of the land in order to be/as a stabilising agent, for the individual to create their own third space of embodied stories by incorporating their own stories with Country's. Meanwhile Biamanga the sister Mountain of Gulaga and significant site, is a place of teaching, 
journeying and healing that tests the shared third space because of the colonial destruction on this site ${ }^{1}$.

An intention of the storying/theoretical approach of Mingadhuga Mingayung was to create, utilise and stabilise the academics' own third space. Country's relationship with the individual is the third space where Country can test their own understandings and relationship to colonial actions and knowledge. The academics looked for and explored similarities in this relationship that focuses on what is felt. The embodied stories encouraged the academics to identify matching/paralleling stories through a spiritual umbilical cord of connection (Author 2015) to reduce Western binary thinking. The non-Aboriginal academics engagement in the Yuin cultural experience with Country helped them to birth a new site and "be a subject occupying multiple sites in culture and history continue to know themselves" (Jacobs 2002, p. 350). The subject is the body of knowing self not just in relation to self, but also in relation to Country. By knowing their own history in relationship to Country, self and colonisation, the academics were assisted in the process of moving into the present to know a respectful reciprocal relationship with Country.

The teachings from the text of the land are at first felt when working in relatedness with the mind, body and spirit. Country has always existed even after colonisation and does not need to be reconstructed. People/visitors to Country on the other hand need to decolonise/reculturalise the logical mind that removes spirit and feelings. Dudgeon and Fielder (2006) argue that, for Aboriginal culture to be re-valued, the lifeblood of Aboriginal culture has to be injected into the colonial system to assist decolonisation.

The embodied stories of and in Country are the essence of Aboriginal life and are a truth, the retelling of the stories keeps them and us alive, to give thanks to the ancients in these stories that were witnessed by our ancestors. A collaborative partnership between academics, Aboriginal people and Country is imperative to embed Aboriginal perspectives. However over time, the respectful reciprocal relationship with Country will in itself help the academics to open their mind (Author 2015), body and spirit to a different and connected view in sharing embodied stories not perspectives.

\footnotetext{
1 On Biamanga a significant cultural tor was blasted and is a very visible site of destruction that places people directly in the devastation caused by colonisation.
} 


\section{The Cultural Experience}

The academics were taken on two field trips ${ }^{2}$ to Gulaga and Biamunga, two significant Yuin cultural sites on the far South Coast of N.S.W. Gulaga is Mother Mountain who holds the Yuin Creation Story and Biamanga is a place of teaching. Elder, Uncle Max Harrison and members of his family (including the researcher) guided the academics through the sites. The guides were led by the text of the land to convey the story of the mountain(s) for the academics to experience. The intention was to place the academics into an Aboriginal education system to experience an interconnecting physical, mental and spiritual approach to learning. For these six nonAboriginal academics this was uncharted space, which required a personal and educational relationship with Gulaga and Biamanga. The experience of learning with non-human being as teachers can develop the skills necessary to be aware of and appreciate self as Country and Country as self (Author 2015) to form a new site of knowledge production.

\section{Researching an Experience with Country}

Two early childhood academics were joined by four other non-Aboriginal academics from a school of education in a regional university to participate in the cultural experience. A study was constructed around their involvement by collecting data through recording pre and post-experience 'cross-cultural yarning' sessions (Walker, Fredericks, Mills \& Anderson 2014) and debriefing/yarning sessions immediately following the cultural experience. An application to the university ethics committee was successful with pseudonyms given to protect the participating academics. As the Aboriginal researcher, I also obtained permission from my Elder and cultural teacher Uncle Max Harrison. The academics were prepared for the cultural experience by yarning about what 'respect' necessitates, in the context of behaviour while within the sites. All six academics agreed to have their conversations included in the research project.

\footnotetext{
2 The actual experience cannot be shared in the context of this paper, as the experience of the nonAboriginal peoples is the focus of the research. For an indication of the actual experience please read Harrison, M. D. \& McConchie, P. (2009). My people's Dreaming: an Aboriginal elder speaks on life, land, spirit and forgiveness. Warriewood, N.S.W, Finch Publishing.
} 
Cross-cultural yarning is an Aboriginal method that involves profound and respectful communicative interactions between Indigenous and nonIndigenous people (Walker et al, 2014). In relation to research, Bessarab and $\mathrm{Ng}$ 'andu (2010) describe yarning as a process whereby,

both the researcher and participant journey together visiting places and topics of interest relevant to the research study. Yarning is a process that requires the researcher to develop and build a relationship that is accountable to Indigenous people participating in the research (p. 38).

In this study yarning was utilised as a method to reveal the relationship between the academics and Yuin Country. Importantly, it provided sensitive (personal) data on the academics' understandings, knowledge and feelings on Aboriginal people and culture. After the visit to Country, the debriefing yarning sessions provided a snapshot of emotions felt during the actual experience on Country to contextualise the post experience yarning.

Through yarning, a reciprocal relationship was able to evolve between Country, researcher and participants to respectfully care for and share their embodied stories of connection. As a researcher, I observed Country's teachings through the academics' yarning from the pre-experiences, de-briefings and post experiences as stories to see the reflection of and relationship with Country within me as the researcher (Author, forthcoming). I identified connectivity, that is, points of understanding through Country's, the academics' and my own story: my truth on how my learning and knowing was enhanced through these interactions. According to Kwaymullina and Kwaymullina (2010) Country shapes all meaning to be true when the story is within its own space. My own cultural relationship with Country prepared me to explore my connections, similarities and differences to the academics' growing relationship with Country. The use of a Western analytical approach towards the yarning extended the capacity of the research to find similarities within the differences. This relationship helped me to identify the nature of the academics' understanding, knowledge and behaviour in relatedness to Country and social justice thinking.

\section{Pre and Post experience Yarning}

The pre-experience yarning used both Yuin and non-Aboriginal discussion/interview rules and protocols to formulate a cross-cultural yarning (Walker et al 2014; Author, 
forthcoming). Arguably, many cultures are familiar with varying forms of storytelling to enhance an equitable relationship arrangement. I chose to model storytelling as a way of prompting the participants to answer questions through story. The following questions guided the process: 'What do you know about Aboriginal people and Aboriginal culture?'; 'If you had to teach Aboriginal perspectives how would you go about it?'

The post yarning session shifted more towards a Yuin mode of yarning, a mode that the academics experienced throughout the research and cultural experience. The postexperience yarning questions evolved from the yarning itself to keep the academics' stories flowing and to maintain the intent of the research. The post experience yarning started with reference to the pre-experience Yarning: 'In our first yarn, we talked about our memories, memories of Aboriginal people and Aboriginal culture. What I would like for us to start yarning about is your present memories on Aboriginal people culture. Has there been a shift?' Thereafter the questions evolved from the academics' stories or responses. The following questions evolved from this process: 'On that, how is your relationship going with Country?'; 'How is everyone dealing with coming from a non-Aboriginal epistemology then engaging in this other way of knowing?'; 'We started talking about self in different ways so how do you think self and Country are connected?; 'How much do you think this (experience) has prepared you at implementing Aboriginal perspectives into the curriculum?'

\section{Debriefing Sessions}

A debriefing session was held on the night the academics walked the sacred mountain Gulaga. The debriefing session for Biamanga was held a week after the visit, due to time constraints for staff to get back to family and work the next day. The debriefing was a yarning circle where the academics shared their stories of the experience. The debriefing question was: 'Could you please reflect on the day by sharing the things that really stood out for you?' Two of the Aboriginal guides were intentionally placed at the start of the circle so they could model how the debriefing session worked with story.

\section{The First Step into a New Relationship: Analysis and discussion}

Stepping into a new relationship in regards to knowing, learning and behaving is a space that goes beyond intention; the individual is invited to be open to feelings and a 
willingness to share. This section explores previous influences described by the academics' on their awareness and understanding of Aboriginal people and culture. Particular attention is given to social justice, especially how it influenced the academics thinking before meeting Country and how this impacted their experience of Country. The academics' personal and pedagogical relationship with Yuin Country is represented in their shared stories to identify any shifts from, what Author (2015) describes as 'legacy pedagogy', that is a pedagogy that is emotive, connective, spiritual and heals through Yuin Country's stories. While many of the factors influencing the shifts in the academics' perspectives go beyond this paper, what was indicated in their stories was a shared recognition that there is a different way of knowing, learning and behaving in relation to Aboriginal knowledge and people, in which they can engage.

\section{Pre-experience Yarning: What do we know?}

The pre-experience cross-cultural yarning established the basis for two significant findings: the academics' own story of relationship with Aboriginal people and that they experienced Country as a living pedagogical entity; and how the academics yarning revealed the influence of social justice thinking on knowing, learning and behaving with Country. Following an Aboriginal traditional process of introduction the pre-experience cross-cultural yarning was begun with questions about place and self; the final question asked the academics about 'their business'. 'What brought them to the project and what did they wanted to achieve?'

I think I have a very strong sense of fairness and social justice but I always feel like in relation to Aboriginal people that my understanding isn't as deep as it could be or should be $\left(\mathrm{Kylie}^{3}\right)$.

I suppose I would like to increase my awareness and my ability to comfortably and confidently express the Aboriginal culture and so on and so forth in a respectful way in my position (Liz).

In these comments, Kylie and Liz reveal how a human centred social justice model underpinned their thinking, and their desire to have an understanding and awareness of Aboriginal knowledge, people and culture. On one hand the comments seem to refer to an internal state, that is, they want inward gratification, as in wanting to learn more because of feelings relating to social justice as overcoming disadvantage. On the other hand, their comments also indicate that they are still very outward (separate) in

\footnotetext{
${ }^{3}$ All participants names are pseudonyms as required by the university ethics committee.
} 
their thinking, because it is about the other, not self. The inward but outward thinking can be interpreted as forward thinking, in the progressive nature of Western thinking. Plumwood (2002) states, "progress is the progressive overcoming or control of this 'barbarian' non-human or semi-human sphere by the rational sphere of European culture and "modernity"' (p. 9). Progressive thinking devalues Country as a present entity, with social justice implying that Aboriginal people are disadvantaged solely because of the human relationships. The social justice mind is focused on future inwards/internal feelings to influence outward actions or influences as a professional. Kylie and Liz want to 'help' the disadvantaged others in a place known as a work environment because of the past (inward) and present (separation).

The need to know more or increase awareness about the separate 'other' is strongly present in these comments while the concept of wanting to connect with Country remains hidden/elided. Connecting is different to knowing and understanding, as these two terms maintain the detachment of Western culture in relationship from the 'other' culture. However, from my observations the academics' intent was to go beyond this point, but at this stage they did not have the language nor conceptual tools to express this meaning; at this stage; it was more like an unknown space somewhere in between the academics' social justice framework and Aboriginal knowledge systems. This in-between space provided a starting point to introduce reflexivity with the aim of moving into examining self as Country, to provide an opportunity to unpack connectivity. Townsend-Cross (2011) argues 'reflexivity is crucial to address the ideological blind spots that may be associated with being a member of the privileged majority' (p. 103). The academics drawing on the knowledge system available to them at this point needed to speak of and share the gift of not knowing or knowing about Aboriginal people and culture. This enabled the researcher to locate an individualised position within a communal ritualised framework (yarning) to find a commencement point of relating to Country.

In contrast to Kylie and Liz's comments, Rachel's statement from the collective story is similar, but contains a small but important contrast.

I would like to know more about the history, and the lives of Indigenous people in this area and I would like to know what they want for themselves for the future (Rachel). 
The potential for change from a social justice perspective to connection or pattern 'thinking' (Mowaljarlai cited in Grieves 2009) was clearer in Rachel's inward and inward thinking statement. Rachel still desired awareness, however she importantly indicated a willingness to remove herself from the privileged social justice position. Rachel's assertion of 'to know what they want for themselves for the future' is crucial for the connection of self in the in-between space to occur with Country. To go beyond social justice thinking the colonial ownership of the in-between space and the uncritical adoption of social justice itself has to be let go. Not needing to know for the inward, outward social justice self, the individual can start to know self with Country therefore to understand that people are in charge of their own connective story, healing and lives.

Overall the academics comments in the pre-experience yarning provided confirmation that social justice is an important model to bring non-Aboriginal people to a space where Aboriginal processes, systems and respect can be introduced to shift the colonial influenced social justice mindset. The context of Country as teacher and pedagogy to inform the skillset to read the text of the land is not evident within the yarning, which was somewhat expected. Importantly their preparedness to acknowledge that they were at the very beginning of knowing opened a pathway to engage in learning through Aboriginal ways of knowing and behaving.

\section{Pre-experience Yarning: Testing the reflexive Self}

'What do you know about Aboriginal people and Aboriginal culture?' This question in the pre-experience cross-cultural yarning provided a platform to examine the academic' memories and constructions of Aboriginal peoples and cultures before engaging in the Mingadhuga Mingayung approach. The following quotes demonstrate how social justice thinking allows for recognition of marginalisation, but are limited in proposing a relationship with Country that would promote an understanding of Aboriginal perspectives.

I initially use the word frustrated, I agree with that, I have a frustration with that in my life I had such limited exposure to Aboriginal people (Jack).

I think that my education in relation to Aboriginal people has been I guess somewhat tokenistic (Kylie).

Jack and Kylie's acknowledgement of their tokenistic understandings of overcoming Aboriginal disadvantage points to their frustration at the limits of their understanding. 
However there is no clear indication of looking at self or reflexivity. Harry's following story snippet provides an example of a subtle change from thoughtlessness, to recognition, to something felt within him-self.

For me it goes very deeply because I hate tokenism and growing up in a smallcolonised Country neighbouring Australia, I grew up a racist, without realising I was and ... As kids we didn't even realise it was racism. (Harry pre-experience)

The positive aspect of the social justice model was clearly at work in Harry's story and importantly Harry, from my observations, was very self-reflexive. Taking ownership of self as being racist opened an avenue for change and demonstrated a great possibility for Harry to initiate another step for examining self from a Yuin framework. The important issue here is that social justice ("I hate tokenism") did establish an opportunity for Harry to identify the historical, political, social and racial context that contributed to his stepping out of the known racism cycle. Shifting the academics' stories subtly is crucial but a deeper movement is required into the 'unknown' Aboriginal framework to remove the notion of the 'other' in the stories being shared. Not knowing the subtleties of another framework presents a blockage to moving beyond social justice thinking.

\section{Pre-experience yarning: Testing self within Aboriginal perspectives}

The yarning moved to examine the academics' understanding and positioning on any previous teaching of Aboriginal perspectives. This was prompted by questions such as: "What is an Aboriginal perspective?; and how would you teach an Aboriginal perspective?' In response Kylie and Sarah said,

It is a dilemma in a way but it is also about you know how we move into cross cultural living and that's what we are really trying to achieve is being able to relate across cultures in a sensitive way from both sides and with a genuineness, so it is with a genuine cross cultural relationship that we develop (Sarah).

We do inject an Aboriginal perspective into classes from time to time without thinking about it just by the questions we raise or the resources we draw on or the experiences we draw on (Kylie).

The academics identified the dilemmas and tensions of working in a space and place that was relatively unknown to them. The statement of 'without thinking' is important to consider, as I would judge Kylie to have been successful in teaching from the perspective of the dominant Western educational policy on Aboriginal peoples. The 'no thinking' suggests no consideration of how self is situated in the curriculum- 
Aboriginal perspective relationship. The resources that are utilised are separate from the academics' lived experience. The 'no thinking' indicates that the academic cannot put the resource content into a context of meaningful engagement and feelings in relation to what is being taught. When feeling is incorporated into teaching a subject or topic with Country's influence, the knowledge is contextualised to impart relevance and meaning to the learning experience. As Harrison and Greenfield (2011) suggest, "quality teaching of Aboriginal perspectives is contingent upon the teacher's conceptualisation of Aboriginal knowledge as that which is always grounded in place and only meaningful in the context in which it is produced" (p. 66) At this point in their experience, social justice thinking has allowed the six academics to present a disconnected resource that has created general inclusivity but that has maintained separation. At the same time social justice thinking led Sarah to recognise her dilemma in wanting to relate across cultures but not knowing how. Knowing that something is unknown or a dilemma is a function of the connecting third space that can lead to learning how to step out of a knowledge system to work alongside another respectfully.

\section{Post-experience yarning: Memories of Learning}

The experience of Country assisted the academics in the post-experience yarning to reflect back on what they did not know about themselves. Primarily this was about their disconnection from Country and its system and process of knowledge creation. The following statement is one example of how Country started to work within the body of Liz after the cultural experience.

I think I had some knowledge and an appreciation from a political perspective of what had happened with invasion with settlement. Some connection with what had taken place before because of other things that I have done. It's really for me now, it's under the skin, it is only just there but it's under the skin. I think by that I mean I have got a new frame of reference.

Liz's "new frame of reference" was a crucial indication of her developing relationship with Country as she started to feel another knowledge system. The Yuin knowledge system is more than just thinking, it is feeling the unseen energies that Country holds. This feeling helped Liz to move circularly through and out of her own knowledge system to continue the two-way learning process. Liz's comment 'it's under my skin' 
resonates with the ways Basso (1996 cited in Morris 2002) describes stories as change agents, a good starting point to show connections.

Tales have a way of almost literally getting under your skin: 'That story is working on you now. You keep thinking about it. That story is changing you now, making you want to live right. That story is making you want to replace yourself' (p. 197).

The stories from Yuin Country got under Liz's skin, which had an effect on her feelings around knowing another framework of learning, an important effect reported by Basso's story on the Apache male.

The academics often coined the term 'difficult to explain' to describe the feeling that happens when the academics did not have, at the time, the linguistic capacity to describe the action happening within the body as it works its way into translation in the mind: the difficult to explain feeling 'under the skin'. The term "replacing yourself" is an important concept for determining the 'success' of the experience and the academics' initiative/willingness to examine self with Country. Replacing yourself cannot be taken literally as it is a long movement over time in which feelings play a significant role. As Martin (2007) states,

Each lifehood stage is an evolvement, a transformation of the previous stage (e.g. childhood evolves from babyhood and conception). It is the dying out of one lifehood stage in order to be birthed into the next. These transformations are not just physical and biological, but also spiritual, emotional, social, cultural and intellectual (p. 18).

In the context of this exploration, feelings are the signposts to assist the academics in adulthood to start learning and knowing in another site of knowledge to replace looking at the other. An important question for this research, then, is whether the academics could initiate a continuing re-placing of self between two sites of knowing to develop a sagacity of self in order for self to embed Aboriginal perspectives respectfully. As Jack succinctly stated,

I guess I have always had the respect but it has been a respect out of just in general, now it is a bit more personal.

Jack and the other academics demonstrated an indirect intent and willingness to proliferate connective sites within their knowledge framework through examining self on a personal level of respect. 
Debriefing and Post experience yarning: Moving from Social Justice to Relationship with Country

The experience of the two cultural sites activated an initial shift in the academics from social justice thinking to examining self in affiliation to the text of the land to form a reciprocal relationship with Country. Styres, Haig-Brown and Blimkie (2013), utilising Graveline's (1998) work, argue from a Canadian position, "a pedagogy of Land starts from the notion of Land as first teacher and as an embodiment of self-inrelation" (Graveline 1998 quoted in Styres et al 2013, p. 40). Every entity from the land has a story that is in relationship with everything else from the land including humans. Understanding this relationship of self to Country will happen within its own pace for each individual. Akin to any formation of a relationship, the introduction has to take place in the appropriate context of the situation, in this case, through the Mingadhuga Mingayung approach. Hill and Mills (2012) describe their own observations as non-Aboriginal academic learning from Country: "place rather than time emerged as the crucial element in developing our understanding of Indigenous cultural competence" (p.70). The story as place will work within the whole body including the mind and spirit. Having an open mind (Author 2015) can work with Country, if logical thinking is kept in tune with the body and spirit, to reveal a meaning for that time within the individual. The essence is time, the story and the individual working on all levels, physical, mind and spirit in oneness. Thereby providing time for feelings, knowing that the learning will make sense when it is ready to occur in its own time, when feelings work their/there way into the mind as meaning.

The debriefing interviews and post yarning were set up to determine and give some time, for the movement of this relationship of self to Country. The intent was to determine a process and system for the academics to extend their individualised story, initiated in the pre-experience yarn, as a practical perspective to be implemented in the curriculum. In response to the question about their post-experience memories of Aboriginal people and culture, the academics talked about a shift within themselves,

So for me that's what, it was very much a political base view of where we are. It's still there but what now has happened to me is it's become more of a personal engagement with Aboriginal, just looking at land and looking at opening my eyes a little bit more to, I'm seeing things I didn't see before (Harry, post-experience) 
So it's like having a new lease on things, one that I didn't have before. (Liz postexperience)

To help the reader put these comments into context the following comments from the debriefing session on Gulaga can give an insight into what happened within the academics.

I was totally absorbed and taken over I guess, it was nearly an out of body experience, words can't sort of explain (Kylie debriefing, Gulaga)

What I saw on the track today, which amazed me, just lots of life everywhere. (Sarah debriefing, Gulaga)

I spend my life looking at goals, doing a doctorate you spend your life looking at deadlines and feeling guilty that you are not reaching them instead of actually stopping and enjoying the wonderful things that are happening in front of you. (Harry debriefing, Gulaga)

The academics were given the time, space, place and silence to see what was in front of them, a relationship that has always been there but not totally visible because the foreign story of colonisation blocks the text of the land. As Hill and Mills (2012) found with their journey on Country, "Reversing colonial history, if only for a nanosecond, this time it was the non-Indigenous who were dislocated and relocated" (p. 72). The nanosecond of reversal indicates that the colonial mind can step into an Aboriginal location to learn. The relocation of Yuin stories into the being of the academics that comes from Country, while on Country, generated something within the academics that could not be totally explained at this stage of their journey. Country's stories continued to be with the academics after leaving the two mountain locations.

I don't know how to describe it, it's growing and it's deeper than it was before. I am more aware perhaps of things that I wouldn't be aware and often quite little things, more respectful. That's what I would say, more than anything else, more respect. (Liz post-experience)

I don't know it's hard to describe. But it's something that I'm doing myself that I'm just, it's become more, it's just part of me now, the way I look around. It's very hard to describe (Harry post-experience)

The 'doing things myself' is an important indication of how the 'legacy pedagogy' (Author 2015) of examining self with Country was at work. The different ways of seeing (Harry) or of being aware (Liz), at this stage of the experience and research, points to a shift in examining self not the 'other'. It doesn't really matter that the 
academics could not explain the change in language, but feeling the change in respect is very relevant to building a relationship with Country as teacher.

At the same time during this discussion, Sarah bravely and respectfully stated that she couldn't understand the spiritual gift that was provided to her, "Logically and in my world it doesn't make sense" (post experience). The logical mind took over to block the feeling and spirit for the embodiment of the story or gift to be received. This is evidence of McLaughlin's (2013) 'default-position', a reverting back into the dominant cultural positioning. The spiritual gift and aligning feelings that goes with the cultural experience was a significant challenge to Sarah's worldview, however Sarah also stated that she is "not going to ignore the gift even though feeling uncomfortable" (post-experience). The important issue here again is feelings; Sarah was still aware of her feelings, thereby open to having a relationship with another site (Country) to produce knowledge. Sarah's story reinforces the challenge of examining feelings in the logical Western world of academia, as this 'spiritual learning' needs to happen in its own time.

The following account from Harry and Rachel summed up the general 'feel' of the yarning around the Yuin experience, that they were only at the start of the journey to utilising Aboriginal ways of knowing to implement Aboriginal perspectives,

... we're putting our toe into the water here ( Harry post-experience).

I think the journey that I have been on has been just a start, a start to open my mind to think in ways that has developed further respect than just awareness (Rachel post-experience).

The academics were taking the first step into engaging in the legacy pedagogy (Author 2015) by sharing their story of relationship with Country and Aboriginal people as their own perspective in teaching Aboriginal perspectives. A challenge for academics and academia is to make space for this relationship to develop both personally and professionally.

\section{Producing a story of relationship as Pedagogy in Aboriginal Education}

The analysis of the yarning created an opportunity to show how the academics could think and feel about Aboriginal culture especially in regards to the concept of a relationship with Country as the producer of story (Author 2015). In addition the yarning sessions also indicated how the initial relationship with Country relieved 
some of the stresses that the academics held about respect of and responsibilities to teaching within the realm of Aboriginal perspectives. As Liz states,

For me, it's deep, that deep feeling that I know I have regained that connection. I have come back from wherever I have been, somewhat hard to describe but it's just that inner feeling of even comfort (post-experience).

This excerpt suggests that Liz has recognised the spiritual feeling that, arguably all people felt for Mother Earth during the centuries of human life. Daes' (2007) exploration of colonisation around the world suggests Westerners have been oppressed and oppressed consciously for centuries about the experience of spiritual independence. Country can help self, feel self again, through a reculturalisation of reconnecting to Mother Earth. Furthermore for Liz, feeling comfortable or safe was very important as it reduced the uncertainty that often occurs in implementing Aboriginal perspectives. In Deer's (2013) research, teacher candidates' concerns about including Canadian Aboriginal perspectives in school was characterised by "fear of failure, discomfort with the subject matter, guilt, and not being Indigenous" (p. 204). The academics' story with Country opened up space and place to share their feelings and thoughts in relationship with Aboriginal people and Country.

Importantly, the comfortable feelings will stay intact if they can maintain respect for Country as the producer of these stories, thereby reducing the prerogative of Western knowledge ownership over Country. The simple statement by Harry, 'where I am at' (post-experience yarn), indicates his relationship with Country as knowledge holder, which can lessen the tension that restricts meaningful Aboriginal educational experiences for all students. Harry can only share what he knows of his own experience with Country at this stage of his learning journey in respect and reciprocation. Just as Hill and Mills' (2012) adventure learning experience at Menindee recognised it as "only the start of what is anticipated will be an ongoing, mutual learning journey between the University and Indigenous communities" (p. 68). The relationship with Country has to be an ongoing, as it is with Aboriginal people and, with the academics in this study, otherwise the Yuin system and process will continue to be ignored.

\section{The Conclusion is just the start}

This study of six non-Aboriginal academics that participated in an experience with Yuin Country produced important evidence and discussion to broaden the directions 
of the discourse on non-Aboriginal people teaching and implementing Aboriginal perspectives. The simultaneous operation of, and substantial departures beyond social justice thinking are paramount to recognising and emphasising Country as a dynamic educational entity. In the context of this study, Western social justice thinking encouraged the academics to recognise the disadvantaged 'other' and how they were positioned and positioned themselves in this top-down framework. For academics to find connectivity with Country, what is required is a reduction in social justice principles that emphasise inward self-gratification. Thereby creating space to place an emphasis on the pedagogy of feeling/ experiencing Country as a site of knowledge production.

To achieve this doesn't necessarily require a state of contestation, conflict, or denial. Rather, a quite different way can be introduced, that is to be an observer, then examine your own behaviour in the particular relationship(s). The academic's own identification of tokenistic or racist behaviour in this research demonstrated the inward action of the Western body in the outward social justice structures of maintaining control. Social justice can be said to play an important role before and after the cultural experience; however when stepping onto Country social justice should remain seated in the academic's knowledge site. This shift in relationship with Country can build another usable site for knowledge production, if the individual does not colonise the experience by separating out the logical mind from emotions.

The Mingadhuga Mingayung experience placed the academics into a learning situation where reliance on the logical mind would disrupt learning. Thereby the examination of social justice principles that lead the academics to participate in the experience was important. On reflection an important aspect that was missing within the investigation was to ask why the academics had not sought such an experience outside their work structures. This would have expanded and intensified the exploration of social justice in the post-experience yarning. As has been argued so far, the learning has to be personally felt with Country, not just seen as a component completed during and for work. If the cultural experience remains in the context of a work requirement then the colonising effects of social justice models are likely to continue (Ben-Ari and Strier, 2010). The outcomes of this research have demonstrated how Country assisted the academics to examine self in relation to Country as they 
moved outside the known political and historical domain to meet Country for the first time, through their observed feelings.

The reduction of social justice thinking occurred within the in-between space created by the academic with Country. Country re-focused the academics' inspection of the Aboriginal 'other' onto an observed examination of self. The place of teaching, Biamanga, triggered this teaching within Harry,

Well it is yourself, you have got to start with respecting who you are, ... it strikes me that is a sensible place to start (debriefing, Biamanga)

The respect of self in relationship with Country leads to connecting with the 'other' through finding similarities, a clear shift from social justice thinking. If respect is shown to the other who embodies Country's stories then the identifying similarities becomes easier to feel and know. Birrell (2006) explains embodiment to Country as a 'response to the place ... predicated on my body as active player, as conduit of teachings, as site of reciprocity with place, as sensate tool of mediation between place and self' (p. 294). Gulaga and Biamanga placed unseen energies upon the academics' body in which the academics had difficulties in trying to explain but could feel.

\section{The process of embedding the embodiment of story into self and the curriculum}

Country assisted the researcher through the identification of self within the legacy pedagogy (Author 2015) to explain how the storied relationship worked with the academics. The academics took their first step towards a new site of knowledge production to re-examine their professional role to embed curriculum for Aboriginal perspectives. In time the reintroduction of Country as a system and process that holds knowledge, the term Aboriginal perspective itself will have to be re-contextualised into this relationship of knowledge dissemination. The embedding of Country in institutions such as universities will not only reinforce an Aboriginal standpoint, it will change how Aboriginal perspectives are embedded. Taking this point further, Aboriginal perspectives as a term will have to be examined if it is to become equal not subordinate, as it is when framed within social justice thinking. Country helps the academic, if an open mind is present, to examine themselves in the in-between spaces. This will assist in examining the relationship with Country especially their position as an academic that holds power and authority in knowledge production and usage. 
This paper has argued that for Aboriginal perspectives to be embedded in university curriculum academics are required to work with relevant Aboriginal knowledge holders. In this relationship, Country is introduced through ceremony to assist the academics to form a new site of knowledge within themselves as self. The process is to find points of connectivity to parallel or work alongside their own knowledge production sites. If the aspects of social justice that are utilised separate thinking/feeling then the connectivity points will continue to be hidden in the colonial cloak of invisibility.

When academics are willing to learn Aboriginal ways of knowing, learning and behaving with support from Aboriginal people they can start to disrupt their own colonial mindset. The group dynamic of the experience and yarning is similar to McLaughlin's (2013) collaborative learning partnerships, that "not only lessens the depth of resistance to one lone educator's professional practice, but also demonstrates a pedagogical relationship built on trust and respect for diverse knowledge systems" (p. 13). The difference, however, from this approach is that the support must eventually rely less on human control to one based more on a relationship with Country. The human (Aboriginal-Country) support element will always be present especially if the academics, when under pressure from their own knowledge system, slip into the safety of what McLaughlin (2013) calls the 'default position' (p.13) of colonial thinking. However the individual can only disrupt their own colonial mindset with Country, with Aboriginal people as the cultural backstops. Social justice thinking was an important term in this research, and was carefully examined in order to reduce paternalistic behaviour when engaging in an interweaving system from Country that connects. At the same time, however, the research also sought to recognise that social justice has a role to initiate the dislodgement or interruption of colonial influence on the Yuin cultural experience. The experience with the Mingadhuga Mingayung approach is promising to create space in university setting to continue this work. Time 'with' and access to Country will be required in order for Country to reveal the system to the academics' own third space (Bhabha 2004) of relatedness. Country with Aboriginal people will guide this process however other guides from Country such as trees, humidity, animals, birds, wind, and other entities that reveal themselves in time will have more emphasis than the human. The respect for the human guides should always remain but it is Country that should be central not humans. 


\section{References}

Australian Curriculum, Assessment and Reporting Authority. (2013). Crosscurriculum Priorities: Aboriginal and Torres Strait Islander histories and cultures. Retrieved 15 April 2015 from http://www.acara.edu.au/curriculum/cross_curriculum_priorities.html Ben-Ari, A. \& Strier, R. (2010). Rethinking Cultural Competence: What Can We Learn from Levinas?, The British Journal of Social Work, 40(7), 2155-2167.

Beresford, Q., Partington, G. \& Gower, G. (2012). Reform and resistance in Aboriginal education. UWA Publishing, Crawley, W.A.

Bessarab, B. \& Ng'andu, B. (2010). Yarning about Yarning as a Legitimate Method in Indigenous Research. International Journal of Critical Indigenous Studies, 3(1), 3750.

Bhabha H. C. (2004) The Location of Culture, London; New York: Routledge Ltd, GB.

Birrell, C. (2006). Meeting country : deep engagement with place and indigenous culture. $\mathrm{PhD}$, University of Western Sydney.

Christie, M. (2010). Teaching from Country, Learning from Country. Learning communities: international journal of learning in social contexts, (2), 6-17.

Daes, E. (2007). Prologue: The Experience of Colonization Around the World. In Battiste M., (Eds), Reclaiming Indigenous Voice and Vision, UBC Press, Vancouver, Toronto.

Deer, F. (2013). Integrating Aboriginal Perspectives in Education: Perceptions of PreService Teachers, Canadian Journal of Education, 36(2), 175-211.

Dudgeon, P. \& Fielder, J. (2006). Third spaces within tertiary places: indigenous Australian studies, Journal of Community \& Applied Social Psychology, 16(5), 396409. 
Grieves, V. (2009). Aboriginal spirituality: Aboriginal philosophy, the basis of Aboriginal social and emotional wellbeing, Cooperative Research Centre for Aboriginal Health, Casuarina, N. T.

Harrison, M. D. \& McConchie, P. (2009). My people's Dreaming: an Aboriginal elder speaks on life, land, spirit and forgiveness. Warriewood, N.S.W, Finch Publishing.

Harrison, N. \& Greenfield, M. (2011). Relationship to place: positioning Aboriginal knowledge and perspectives in classroom pedagogies, Critical Studies in Education, 52(1), 65-76.

Hill, B. \& Mills, J. (2013). Situating the 'Beyond': Adventure-Learning and Indigenous Cultural Competence, Discourse: Studies in the Cultural Politics of Education, 34(1), 63-76.

Jacobs (2002) Introduction: After Empire, 345- 353. In Anderson, K. (Edt) Handbook of cultural geography, London: SAGE Publications Ltd, London, 2003.

Kwaymullina, A. \& Kwaymullina, B. (2010). Learning to read the signs: law in an Indigenous reality. Journal of Australian Studies, 34(2), 195-208.

Lampert, J., Burnett, B., Martin, R. \& McCrea, L. (2014). Lessons from a face-to-face meeting on embedding Aboriginal and Torres Strait Islander perspectives: 'A contract of intimacy', Australasian Journal of Early Childhood, 39(1), 82-88.

Lowe, K. \& Yunkaporta, T. (2013). The inclusion of Aboriginal and Torres Strait Islander content in the Australian National Curriculum: A cultural, cognitive and socio-political evaluation. Curriculum Perspectives, 33(1), 1-14.

Martin, K. 2007, "Ma(r)king Tracks and Reconceptualising Aboriginal Early Childhood Education: An Aboriginal Australian Perspective", Childrenz Issues: Journal of the Children's Issues Centre, vol. 11, no. 1, pp. 15-20.

McLaughlin, J., M. (2013) 'Crack in the pavement': pedagogy as political and moral practice for educating culturally competent professionals, International Education Journal: Comparative Perspectives, 12(1), 249-265.

McLaughlin, J. M. \& Whatman, S. L. (2011) The potential of critical race theory in 
decolonizing university curricula, Asia Pacific Journal of Education, 31(4), 365-377.

Morris, D.B. (2002), Narrative, Ethics, and Pain: Thinking with Stories. In Charon, R. \& Montello, M. (Eds) Stories matter: the role of narrative in medical ethics, (pp. 196218) Routledge Ltd, GB.

Moreton-Robinson, A M., Singh D., Kolopenuk, J., Robinson, A. \& Walter, M. (2012) Learning the Lessons? Pre-Service Teacher Preparation for Teaching Aboriginal and Torres Strait Islander Students. A Report prepared for the Division of Indigenous Education and Training Futures - Queensland Department of Education, Training and Employment, Indigenous Studies Research Network, Queensland University of Technology. QUT Indigenous Studies Research Network.

Plumwood, V. (2002). Decolonisation Relationships with Nature, PAN: Philosophy Activism Nature, (2), 7-30.

Nakata, M. (2013). The Rights and Blights of the Politics in Indigenous Higher Education. Anthropological Forum: A Journal of Social Anthropology and Comparative Sociology, (23)3, 289-303.

Smith, L.T. (2012). Decolonizing methodologies: research and indigenous peoples, Zed Books, London.

Styres, S., Haig-Brown, C. \& Blimkie, M. (2013), Towards a pedagogy of land: the urban context, Canadian Journal of Education, 36(2), 34-67.

Townsend-Cross, M. (2011). Global Citizenship- No Guarantees: oppressed knowledges and privileged learners 87-108. In Shiel, C. (Eds), Global Vision, Local Action: Education for Sustainable Development and Global Citizenship. Proceedings of the Fourth International Conference Bournemouth, September 2011 Centre for Global Perspectives Bournemouth University

Walker, M., Fredericks, B., Mills, K. \& Anderson, D. (2014). "Yarning" as a Method for Community-Based Health Research With Indigenous Women: The Indigenous Women's Wellness Research Program", Health Care for Women International, 35(10), 1216-1226. 
Williamson, J. \& Dalal, P. (2007). "Indigenising the Curriculum or Negotiating the Tensions at the Cultural Interface?: Embedding Indigenous Perspectives and Pedagogies in a University Curriculum", Australian Journal of Indigenous Education, 36(Supplementary), 51-58. 